J Res Dentomaxillofac Sci

JRDMS Journal of Research in Dental and Maxillofacial Sciences

\title{
In-vitro Comparison of the Impact of Four Types of Resin \\ Composite on the Repaired Bond Strength and Surface Roughness After Sandblasting
}

khorgami K ${ }^{1}$, Sadaghiani $\mathbf{M}^{2}$, Nemati Anaraki $S^{2}$

${ }^{1}$ Specialist in Restorative.

${ }_{2}^{2}$ Assistant Professor, Restorative Dept, Member of Dental Materials Research Center,Dental Branch of Tehran, Islamic Azad University, Tehran, Iran.

\begin{tabular}{l}
\hline ARTICLE INFO \\
\hline Article Type \\
Orginal Article \\
\hline Article History \\
Received: May 2015 \\
Accepted: August 2015 \\
ePublished: Junuary 2016
\end{tabular}

Keywords:

Resin composite

Sandblasting

Surface roughness

Bond strength

\begin{abstract}
Background and Aim: One of the major problems with resin composite restorations is the weakness of bonding between the new and aged composites. Since appropriate micromechanical retention is necessary for the repair of aged resin composite restorations, the level of surface roughness after sandblasting can be influential in this regard. Considering the diverse composition of available resin composites in the market, the present study was performed to compare the impact of four resin composite types: Micro-hybrid (Z250), Nano-fill (Z350XT), Nano-hybrid (Z250XT) and Silorane-base (p90) on the repaired bond strength and surface roughness after sandblasting.

Methods and Materials: In this in-vitro experimental study, 44 resin composite discs with the diameter of $6 \mathrm{~mm}$ and height of $2 \mathrm{~mm}$ were divided to 4 groups of Microhybrid, Nano-fill, Nano-hybrid and Silorane-base and from 11 samples of each resin composite type, one sample was evaluated for surface roughness level before and after sandblasting with Atomic Force Microscope (AFM) and 10 samples were tested for shear bond strength in universal testing machine.

Results:The findings indicated that Micro-hybrid resin composite had the highest shear bond strength $(37.8 \pm 6.4 \mathrm{MPa})$ followed respectively by Nano-fill (30 \pm 3.8 $\mathrm{MPa})$, Silorane-base $(17.9 \pm 4 \mathrm{MPa})$ and Nano-hybrid composites $(7.6 \pm 1.9 \mathrm{MPa})$. The differences between all groups were significant $(\mathrm{p}<0.000)$.

Before sandblasting, Nano-hybrid type had the highest level of surface roughness (505 $\pm 154 \mathrm{~nm})$ and the lowest value was related to Micro-hybrid resin composite $(94 \pm 35 \mathrm{~nm}) \quad(\mathrm{p}<0.000)$. After sandblasting, Nano-fill $(1997 \pm 288 \mathrm{~nm})$, Silorane-base, Micro-hybrid and Nano-hybrid composites $(1284 \pm 645 \mathrm{~nm})$ showed the highest increase in surface roughness, respectively $(\mathrm{p}<0.4)$.

Conclusion: In the present study, sandblasting caused a significant increase in the surface roughness of the four studied resin composite types. Despite the lowest surface roughness of Micro-hybrid type, it showed the highest bond strength amongst other composites after sandblasting.
\end{abstract}

Please cite this paper as:

khorgami K, Sadaghiani M, Nemati S. In vitro comparison of the impact of four types of resin composite on the repaired bond strength and surface roughness after sandblasting. J Res Dentomaxillofac Sci.2016;1(1):9-16.

*Corresponding author:

khorshid khorgami,

Tel: 09123802719

Email: khorshidkh@yahoo.com 


\section{Introduction:}

One of the major problems with resin composite restorations is the weakness of bonding between the new and aged composites. Since appropriate micromechanical retention is necessary for the repair of aged resin composite restorations and as the chemical bond alone cannot provide adequate retention, the amount of surface roughness of resin composite can influence the bond strength between new and aged resin composite restorations. ${ }^{(1)}$ Nowadays, resin composites are widely being used. ${ }^{(1,2)}$ Physical and mechanical properties of resin composites have been improved greatly during the past 10 to 20 years.

Nevertheless, oral enzymes can destruct their matrix. ${ }^{(3)}$ Therefore, eventually the old restoration needs to be repaired or replaced and on the other hand, since the replacement of these restorations is time consuming and leads to loss of some dental structure, repair of these restorations is preferred over their replacement. ${ }^{(4-7)}$ The important factor is the bond strength between the new and aged resin composites. ${ }^{(8)}$

Usually, bonding between two resin composite layers is possible in the presence of an oxygen inhibited non-polymerized surface, and since old restorations lack this surface, various techniques have been presented for surface treatment. ${ }^{(9,10)}$ The importance of surface treatment is in the increase of micromechanical bond between the new and old resin composite restorations. ${ }^{(1,7,8)}$

Numerous studies have been performed to introduce the best surface treatment technique. The evaluated techniques include the use of diamond burs, sandblasting with $50 \mu$ aluminum oxide particles, sandblasting with aluminum oxide particles covered with silica (cojet) and etching with hydrofluoric acid. ${ }^{(1-4,9)}$

In multiple studies, sandblasting has been introduced as the best surface treatment method for the aged resin composite but considering the different composition of resin composites and differences in the size and type of filler particles such as (Macro-filled, Micro-filled, Microhybrid, Nano-fill and Nano-hybrid) and with the invention of novel Silorane-base composites containing different compositions, sandblasting can produce surfaces with different degrees of surface roughness. ${ }^{(8)}$

Considering that a comprehensive study on simultaneous evaluation of resin composite surface roughness and bond strength after sandblasting is not available, the present study was performed to compare the impact of resin composite types on bond strength and surface roughness after sandblasting.

\section{Methods and Materials:}

This in-vitro experimental study was performed on sandblasted resin composite samples. 44 resin composite discs, comprising of Nano-hybrid (Filtek Z250 xt), Nano-fill (Filtek Z350XT), Micro-hybrid (Filtek Z250) and Silorane-base (Filtek p90) were selected. The discs were placed inside a mold with $6 \mathrm{~mm}$ diameter and $2 \mathrm{~mm}$ height, which was fixed firmly on a glass slab. In all samples, the resin composite was placed using a plastic instrument without any contamination and was covered with a Mylar strip before curing. Then a glass slab was placed on the top to provide a smooth surface and to remove the excessive composite. Each sample was light cured with an LED light curing device (Star Light Pro; Mectron, Italy) with $600 \mathrm{mw} / \mathrm{cm}^{2}$ intensity and no distance from the surface. The intensity of the device was controlled with a radiometer during each curing. Curing duration was adjusted according to the manufacturer's instruction. After mold removal, all samples were polished with coarse, medium, fine and super fine soflex discs (3M ESPE) in a way that each disc was in contact with the specimen for 20 seconds under light pressure with back and forth movements. Samples were kept in distilled water at $37^{\circ} \mathrm{C}$ for 24 hours. Then, the samples were thermo-cycled for 5000 rounds at $5-55^{\circ} \mathrm{C}$ for 30 seconds for each bath with 10 seconds transferring time. ${ }^{(11)}$

From 11 samples of each resin composite type, one sample was selected to evaluate the level of surface roughness before and after sandblasting with Atomic Force Microscope (AFM, DMEDenmark) and then the samples were sandblasted with $50 \mu$ aluminum oxide powder (Ronving, Denmark) with the use of micro sandblaster intraoral 


\section{Specifications of resin composite types used in the present study}

\begin{tabular}{|c|c|c|c|}
\hline Materials & Composition & Type & Manufacturer \\
\hline $\begin{array}{l}\text { Filtek } \\
\text { Z250 }\end{array}$ & $\begin{array}{l}\text { Matrix:BISGMA,UDMA,TEGDMA } \\
\text { and BIS-EMA } \\
\text { Filler:SILICA,Zirconia( } 0.19- \\
\text { 3/3micron,60\% by wt) }\end{array}$ & Microhybrid & 3M/ESPE \\
\hline $\begin{array}{l}\text { Filtek } \\
\text { Z350XT }\end{array}$ & $\begin{array}{l}\text { Matrix:BisGMA,UDMA,TEGDMA, } \\
\text { Ethyl methacrylates } \\
\text { Filler:aggregated zirconia/silica } \\
\text { fillers(5-20 nm),non aggregated silica } \\
\text { fillers, }(20 \mathrm{~nm} ; 59.5 \mathrm{vol} \%)\end{array}$ & Nanofill & $3 \mathrm{M} / \mathrm{ESPE}$ \\
\hline $\begin{array}{l}\text { Filtek } \\
\text { Z250 XT }\end{array}$ & $\begin{array}{l}\text { Matrix:Bis-EMA, Bis-GMA, UDMA, } \\
\text { TEGDMA } \\
\text { Filler: } \mathrm{SiO} 2 \text { Nanosilica filler, } \\
\mathrm{ZrO} 2 / \mathrm{SiO} 2 \\
\text { Nanoclusters }(0.02-0.075 \mathrm{~lm}) \\
\text { Filled } 78.5 \% \text { by wt } \\
\end{array}$ & Nano hybrid & $3 \mathrm{M} / \mathrm{ESPE}$ \\
\hline $\begin{array}{l}\text { Filtek } \\
\text { p90 }\end{array}$ & $\begin{array}{l}\text { Silorane resin Quartz, } \\
\text { Yttrium Fluoride }(0.47 \text { micron }) \\
\text { Filler:Fine particle }(60.2 \% \text { by w })\end{array}$ & Silorane base & 3M/ESPE \\
\hline
\end{tabular}

sandblasting instrument (Dentoprop Ronving, Denmark) for 5 seconds from $5 \mathrm{~mm}$ distance at 90 degrees angle. To provide a fixed distance for all samples, they were placed inside a transparent plastic rod with the inner diameter of $6 \mathrm{~mm}$ and $5 \mathrm{~mm}$ height along with $2 \mathrm{~mm}$ space for the sample and $3 \mathrm{~mm}$ space for sandblasting. ${ }^{(11)}$ All the stages of sandblasting were performed by one operator. In AFM technique, the digital instruments were activated in non-contact mode to obtain topographic images from the selected areas on the desired surfaces. This instrument has been equipped with a scanner with maximum values of $100 \times 100 \times 5 \mu \mathrm{m}$ in xyz dimensions. To measure the values of surface roughness, the tip of the instrument moved across the surface and images were obtained.

The coordinates of three points on the same surface on the center of the specimen were determined and the mean values were used for statistical analysis. A silicon probe with normal constant curvature was used for image taking. The amount of surface roughness ( $\mathrm{Ra}$ or average height in profile) was reported by the device. ${ }^{(12)}$

The surfaces of the remained samples (10 samples from each resin composite type) were etched with $37 \%$ phosphoric acid for 30 seconds and were rinsed with water for 30 seconds and were dried with air pressure from $5 \mathrm{~mm}$ distance for 10 seconds. ${ }^{(13)}$ Adper Single Bond 2 was applied on the surfaces of Micro-hybrid, Nano-fill and Nano-hybrid composites and was cured for 10 seconds. Then, the samples were placed inside an especial aluminum mold with $4 \mathrm{~mm}$ height and the new resin composites with $2 \mathrm{~mm}$ thickness were added and cured. In Silorane-base samples, the primer of $\mathrm{p} 90$ adhesive system was applied on the surface of old resin composite and was cured for 10 seconds and then the bonding of p90 adhesive system was applied and cured for 10 seconds. Then, the samples were placed inside an aluminum mold with $4 \mathrm{~mm}$ height and the new resin composites with $2 \mathrm{~mm}$ thickness were added and cured.

Afterwards, the samples were mounted in molds using self-curing acrylic resins and were placed in universal testing machine (ZwickRoe$11 \mathrm{Z050}$, Germany) and a force with $1 \mathrm{~mm} / \mathrm{min}$ speed was applied by a blade to the interfaces of the samples and after observing the first bond fracture between the old and new composites, the shear bond strength was recorded in $\mathrm{MPa} .{ }^{(7)}$ ANOVA test was used for statistical analysis. 


\section{Results:}

The obtained values after evaluation of surface roughness in four resin composite types showed that before sandblasting, the maximum surface roughness was related to Nano-hybrid resin composite (Z250xt) which equaled $505 \pm 154 \mathrm{~nm}$ and the minimum surface roughness was appointed to Micro-hybrid resin composite (Z250) which equaled $94 \pm 35 \mathrm{~nm}$. The ANOVA test showed that the values of composites' surface roughness were significantly different before sandblasting $(\mathrm{p}<0.001)$.

After sandblasting, the maximum surface roughness was detected in Nano-fill resin composite (Z350XT), which equaled $1997 \pm 288 \mathrm{~nm}$ and the minimum surface roughness was attained for Nano-hybrid type (Z250xt) that equaled $1284 \pm 645 \mathrm{~nm}$, The surface roughness of Z350XT was $713 \mathrm{~nm}$ more than that of Z250xt. ANOVA test showed that this difference was not statistically significant $(\mathrm{p}<0.4)$. (Table 1$)$

Table 1- Amount of surface roughness (nm) divided by resin composite type

\begin{tabular}{ccccc}
\hline $\begin{array}{c}\text { Resin comp } \\
\text { osite type }\end{array}$ & Before sandblasting & \multicolumn{2}{l}{ After sandblasting } \\
\hline & Values & $\mathrm{cv}$ & Values & $\mathrm{cv}$ \\
\hline $\mathrm{Z} 250$ & $94 \pm 35$ & 37 & $1303 \pm 228$ & 17 \\
\hline $\mathrm{Z} 250 \mathrm{xt}$ & $505 \pm 154$ & 30 & $1284 \pm 645$ & 50 \\
\hline $\mathrm{Z} 350 \mathrm{XT}$ & $193 \pm 77$ & 39 & $1997 \pm 288$ & 14 \\
\hline $\mathrm{p} 90$ & $364 \pm 227$ & 62 & $1414 \pm 821$ & 58 \\
\hline $\mathrm{P}$ value & $\mathrm{P}<0.001$ & & $\mathrm{p}<0 / 4$ & \\
\hline
\end{tabular}

Based on the assessment of the Coefficient of Variation (CV) before sandblasting, homogeneity of Z250xt was the highest $(\mathrm{CV}=30)$ and the lowest homogeneity was related to $\mathrm{p} 90$ resin composite $(\mathrm{CV}=60)$. After sandblasting, the lowest homogeneity was again related to $\mathrm{p} 90$ resin composite $(\mathrm{CV}=58)$ and the highest value was related to $\mathrm{Z350XT}(\mathrm{CV}=14)$. (Table 3 and figure 1, A-H) Also, assessment of the results of shear bond strength test showed that the highest shear bond strength was related to $\mathrm{Z} 250(37.8 \pm 4.6 \mathrm{MPa})$ and the lowest value was related to Z250XT (7.6 \pm 1.9 $\mathrm{MPa})$. ANOVA test proved that this difference was statistically significant $(\mathrm{p}<0.000)$ and POST HOC test showed the differences between Z250 group and other three groups as well as the differences between Z350XT and p90 and also the differences between $\mathrm{p} 90$ and Z250XT, were all significant $(p<0.001)$. Based on the assessment of the $\mathrm{CV}$, the highest homogeneity was related to Z250 scoring 12 and the highest non homogeneity was detected in Z250XT and equaled 25 . (Table 2)

Table 2- bond strength (MPa) based on resin composite type

\begin{tabular}{ccc}
\hline $\begin{array}{c}\text { Resin } \\
\text { composite } \\
\text { type }\end{array}$ & Values & $\begin{array}{c}\text { Coefficient } \\
\text { of variation }\end{array}$ \\
\hline $\mathrm{Z} 250$ & $37.8 \pm 4.6$ & 12 \\
\hline $\mathrm{Z} 250 \mathrm{XT}$ & $7.6 \pm 1.9$ & 25 \\
\hline $\mathrm{Z} 350 \mathrm{XT}$ & $30 \pm 3.8$ & 12 \\
\hline $\mathrm{p} 90$ & 17.49 & 22 \\
\hline $\mathrm{P}$ value & $\mathrm{P}<0.000$ & - \\
\hline
\end{tabular}

\section{Discussion:}

Many studies have shown that composite's surface condition plays an important role in the bond strength between the new and aged restorations, and the interstitial bond between resin composite layers decreases gradually due to conditions in oral environment such as humidity and temperature variations. ${ }^{(14)}$ In evaluation of bonding between new and aged resin composite restorations, factors such as resin composite type, surface treatment, interstitial adhesive substance, the age of the former restoration and the interaction between these factors should be considered. 
$(8,15)$ The new resin composite cannot bond with the old one without surface treating the aged resin composite, and it seems that proper micromechanical bonding on the surface of the old resin composite is the most important factor in achieving high bond strength. ${ }^{(7)}$

The results of the present study showed that sandblasting with aluminum oxide particles increased surface roughness in all of the studied resin composite samples and the highest level of surface roughness was related to Z350XT (1997士 $288 \mathrm{~nm}$ ) and the lowest amount was related to Z250XT (1284 $\pm 645 \mathrm{~nm})$. Moreover, the highest bonding strength was for Z250 (37.8 $\pm 4.6 \mathrm{MPa})$, Z350XT $(30 \pm 3.8 \mathrm{MPa})$, p90 $(17.9 \pm 4 \mathrm{MPa})$ and Z250XT (7.6 $1.9 \mathrm{MPa})$ respectively and these variations were statistically significant amongst all groups.

Based on our findings, no similar study has been conducted on the impact of sandblasting with aluminum oxide powder on the surface roughness of the mentioned resin composites. However, in similar studies the surface roughness of some types of resin composite has been evaluated with different mechanical surface treatment methods.

In a study by Janus et al the surface roughness and morphology of three Nano-composites were evaluated after two different surface treatments with AFM. They concluded that the composition of resin composite especially the amount and size of filler particles affect the surface roughness of different resin composites. ${ }^{(16)}$ This finding is in line with other studies as well as ours. ${ }^{(17-19)}$ Also in the study by Janus et al, the use of Nano particles in the composition of resin composite did not necessarily improve the surface properties of resin composite and this finding is also in line with ours. ${ }^{(16)}$

In a study by Loomas and colleagues, in contrast to our results, Nano-fill resin composite showed the lowest amount of surface roughness after surface treatment. ${ }^{(17)}$ The reason for this difference can be attributed to different resin composite types, surface treatment technique and different aging processes in the two studies.
Duarte et al. concluded that Silorane-base resin composite with the average filler size of $0.55 \mu \mathrm{m}$ can have surface roughness similar to Microhybrid resin composite with the same filler size.

(19) Correspondingly in our study, the amount of surface roughness after sandblasting was reported to be in a close range for Micro-hybrid and Silorane-base composites.

Senawong et al. assessed the surface roughness of Nano-fill and Nano-hybrid composites and found that surface roughness showed no significant difference between polished and non-polished composites, and for Nano-fill resin composite no difference in surface roughness was detected between the two different polishing methods and also in the non-polished surfaces ${ }^{(11)}$ which contradicts our findings. This difference can be attributed to the difference between the methods used for surface treatment.

Similar studies have been conducted on the repaired bond strength and the effect of surface roughness on bond strength in resin composites, which have revealed comparable results to the outcomes of our study. ${ }^{(17-20)}$ Sinval et al. showed that the highest bond strength was for Microhybrid resin composite and the lowest amount of bond strength was related to Nano-hybrid type, ${ }^{(15)}$ which is in line with our findings.

Different studies showed that sandblasting with aluminum oxide significantly increases the micromechanical retention and increases the bond strength after repair, ${ }^{(7,14,15,20)}$ which were in line with our results indicating that after sandblasting the lowest amount of surface roughness was related to Nano-hybrid Z250XT composite.

Our study indicated that surface roughness significantly increased in the four resin composite types after sandblasting which shows that despite differences in composites regarding the composition and size of fillers, sandblasting with aluminum oxide powder can be a reliable surface treatment method to increase micromechanical retention and repaired bond strength. Nevertheless, shear bond strength doesn't necessarily increase with increased surface roughness. As mentioned before, Micro-hybrid resin composite 
with lower surface roughness showed the highest amount of shear bond strength after sandblasting compared to Nano-fill and Silorane-base composites.

Previous studies have shown that the size of fillers can be influential in improving the repaired bond in composites and it seems that larger fillers can improve the bond strength between the new and aged restorations ${ }^{(21)}$ as it was shown for Micro-hybrid resin composite with larger filler particles even though these larger fillers can lead to higher surface roughness in Z250 compared with other composites. ${ }^{(11)}$

In the present study, Silorane-base resin composite was in the third place regarding bond strength and it was in the second place regarding surface roughness after sandblasting. Palasuk et al. stated that bond strength of methacrylate-base resin composite is higher without surface treatment. However, Silorane-base resin composite responds better to surface treatment methods such as sandblasting and provides higher bond strength. (20) Similarly, our study showed that Silorane-base resin composite had higher surface roughness after sandblasting compared with Micro-hybrid and Nano-hybrid resin composites. However, lower bond strength compared with $\mathrm{Z} 250$ and Z350XT can be attributed to the nonhomogenized distribution of surface roughness in p90 composite. Higher bond strength of this resin composite compared with Z250XT can be attributed to the higher amount of surface roughness in p90 in contrast to Z250 and the similarity of surface homogeneity. The reason for the higher roughness of Silorane-base resin composite can be attributed to lower bond strength between the fillers and the matrix which are susceptible to debonding and separation when exposed to aging and surface treatment methods which also can be a reason for surface destruction and increased surface roughness of this composite. ${ }^{(22)}$

Both aging processes in the present study i.e. keeping in distilled water and thermo-cycling can destruct Nano-fill and Silorane-base composites and increase the surface roughness.

As mentioned before, despite less inclination for water absorption in Silorane-base composites, weaker connection between the fillers and matrix and their debonding during the aging process can lead to higher surface roughness. ${ }^{(23)}$

In laboratory experiments, the shear bond strength between resin composite and etched enamel and primed dentinal surfaces has been reported to be 20 to $30 \mathrm{MPa}$ and the main cause of this bond is micromechanical retention and permeation of resin into enamel and dentin structure. ${ }^{(22)}$ This kind of bonding is formed in etched dentin due to permeation of resin into inter-tubular area and the formation of hybrid layer to the depth of 0.1 to $5 \mu \mathrm{m}$, with a similar mechanism to the creation of surface roughness to provide higher repaired bond strength. ${ }^{24,25)}$ Studies have revealed that proper repaired bond strength in composites is approximately equal to the bond strength between resin composite and etched enamel. ${ }^{(20)}$

According to the above statements, three resin composite types in our study (Micro-hybrid, Nano-fill and Silorane-base) had acceptable bond strengths but the bond strength of Nano-hybrid type was below the expected value. The reason may be the different effect of sandblasting on the surface of this resin composite which produces a surface with a very non homogenized roughness distribution, which can lead to abnormal stress distribution on the experimented surface and premature fracture in the sample. Nevertheless, the experimental condition should also be considered because in shear bond strength tests, a wide range of results can be obtained in different parts of the same material. ${ }^{(25-27)}$ Therefore, further investigations are needed in this regard.

\section{Conclusion:}

In the present study, Sandblasting caused a significant increase in surface roughness of the four studied resin composite types. Despite the lowest amount of surface roughness in Micro-hybrid composite, it showed the highest bond strength among other composites after sandblasting. 


\section{Acknowledgments}

The authors would like to thank Dental research center of Tehran university and The AFM center of Iran university of science and Technology for the laboratory work.

\section{Conflict of interests}

The authors of this article certify that they have no proprietary, financial, or other personal interest of any nature or kind in any product, service, and/or company that is presented in this article.

\section{References:}

1.Celik C, Cehreli SB, Arhun N.Resin composite repair: Quantitative microleakage evaluation of resinresin and resin-tooth interfaces with different surface treatments. Eur J Dent 2015; 9(1): 92-9.

2.Frankenberger R,Kramer N,Ebert J,Lohbauer U,Kappel S,Tenweges S,et al.Fatigue behavior of the resin-resin bond of partially replaced,resin-based composite restoraons.Am J Dent 2003;16(1):17-22.

3.Ozcan M,Alander P,Vallittu PK,Huyamans MC,Kalk W.Effect of three surface conditioning methods to improve bond strength of particulate filler resin composites.J Mater sci Mater Med 2005;16(1):21-7.

4.Hori S,Minami H,Minesaki Y,Matsumura H,TanakaT.Effect of hydrofluoric acid etching on shear bond strength of an indirect resin composite to an adhesive cement. Dent Mater J 2008 ;27(4):51522.

5.Lynch CD,Blum IR,Frazier KB,Haisch LD,Wilson NH.Repair or replacement of defective direct resinbased composite restorstions:contemporary teaching in U.S and Canadian dental schools.J Am Dent Assoc 2012;143(2):157-63.

6.Tyas MJ,Anusavice KJ,Frenchen JE,Mount GJ.Minimal intervention dentistry-a review.FDI Commission project 1-97.Int Dent J 2000;50(1):1-12.

7.RathkeA,TyminaY,Haller B.Effect of different surface treatments on the composite-composite repair bond strength. Clin Oral Investig 2009 ;13(3):317-23. 8.Papacchini F, Dall'Oca S, Chieffi N, Goracci C, Sadek FT, Suh BI, et al. Composite-to-composite micro tensile bond strength in the repair of a micro filled hybrid resin: effect of surface treatment and oxygen inhibition J Adhes Dent 2007;9(1):25-31.
9.Lucena-Martín C1, González-López S, NavajasRodríguez de Mondelo JM. The effect of various surface treatments and bonding agents on the repaired strength of heat-treated composites. J Prosthet Dent 2001; 86(5):481-8.

10.Cramer N.B, Stansbury J.W, Bowman C.N.Recent Advances and Developments in Composite Dental Restorative Materials. J Dent Res 2011;90(4):402-16. 11.Senawongse P, Pongprueksa P. Surface Roughness of Nanofill and NanohybridResin Composites after Polishing and Brushing. J Esthet Restor Dent 2007; 19(5):265-75.

12.Tholt de Vasconcellos B, Miranda-Junior WG, Prioli R, Thompson J, Oda M. Surface roughness in ceramics with different finishing techniques using atomic force microscope and profilometer. Oper Dent 2006;31(4):442-9.

13.Bonstein T, Garlapo D, Donarummo J Jr, Bush PJ.,Evaluation of varied repair protocols applied to aged composite resin.J Adhes Dent 2005;7(1):41-9.

14.da Costa TR, Serrano AM, Atman AP, Loguercio $\mathrm{AD}$, Reis A.Durability of composite repair using different surface treatments. J Dent 2012;40(6):513-21. 15.Rodrigues SA Jr, Ferracane JL, Della Bona A .Influence of surface treatments on the bond strength of repaired resin composite restorative materials. Dent Mater 2009;25(4):442-51.

16.Janus J, Fauxpoint G, Arntz Y, Pelletier H, Etienne O. Surface roughness and morphology of three nanocomposites after two different polishing treatments by a multitechnique approach.Dent Mater 2010;26(5):416-25.

17.Loomans BA, Cardoso MV, Opdam NJ, Roeters FJ, De Munck J, Huysmans MC, Van Meerbeek B. Surface roughness of etched composite resin in light of composite repair. J Dent 2011;39(7):499-505.

18.Giacomelli L, Derchi G, Frustaci A, Orlando B, Covani U, Barone A, De Santis D, Chiappelli F. Surface Roughness Composites after Different Polishing Protocols: An Analysis with Atomic Force Microscopy. Open Dent J 2010; 4: 191-4.

19.Duarte S Jr, Botta AC, Phark JH, Sadan A.Selected mechanical and physical properties and clinical application of a new low-shrinkage composite restoration. Quintessence Int 2009;40(8):631-8.

20.Palasuk J, Platt JA, Cho SD , Levon JA, Brown DT , Hovijitra ST. Effect of Surface Treatments on 
Microtensile Bond Strength of Repaired Aged Silorane Resin Composite. Oper Dent 2013;38(1):91-9. 21.Rodrigues SA Jr, Ferracane JL, Della Bona A. Influence of surface treatments on the bond strength of repaired resin composite restorative materials. Dent Mater 2009;25(4):442-51.

22.Weinmann W, Thalacker C, Guggenberger R.Siloranes in dental composites.J Dent Mater 2005;21(1):68-74.

23.Yusuf F, Srirekha A, Hegde J, Karale R, Bashetty $\mathrm{K}$, Adiga S. Effect of alcoholic and non-alcoholic beverages on the wear and fracture toughness of teeth and resin composite materials: In vitro study.JRD 2013;1(1): 11-7.

24.Bayne S C. Beginnings of the dental composite revolution. J Am Dent Assoc 2013;144(8):880-4.

25.Swift EJ Jr .Dentin/enamel adhesives: review of the literature . Pediatric Dent 2002; 24(5) 456-61.

26. Özel Bektas Ö, Eren D, Herguner Siso S, Akin GE.Effect of thermocycling on the bond strength of composite resin to bur and laser treated composite resin.Lasers Med sci 2012;27(4):723-8.

27.Lainović T, Vilotić M, Blažić L, Kakaš D, Marković D, Ivanišević A. Determination of surface roughness and topography of dental resin-based nanocomposites using AFM analysis. Bosn J Basic Med Sci 2013;13(1):34-43. 